\title{
O espectador imparcial de Adam Smith e o observador ideal de John Rawls: Uma crítica à ética utilitarista
}

\author{
Solange Regina Marin \\ Professora - Universidade Federal de Santa Maria (PPGE-UFSM) \\ Endereço: Rua Marechal Floriano Peixoto, 1750 - Sala 611 - Santa Maria/RS - Brasil \\ CEP: 97015-372 - E-mail: marin@smail.ufsm.br
}

\section{André Marzulo Quintana}

Auditor Público do TCE-RS

Endereço: Av. Protásio Alves, 1398 - Apto. 805 - Bairro Petrópolis, Porto Alegre/RS - Brasil CEP: 90410-005 - E-mail: andremq@gmail.com

\section{Cezar Augusto Pereira dos Santos}

Professor - Universidade Comunitária da Região de Chapecó (UNOCHAPECÓ)

Endereço: Rua 14 de agosto, 1940 - D - Bairro Esplanada - Chapecó/SC - Brasil

CEP: 89812-435 - E-mail: cezarsantos1975@unochapeco.edu.br

Recebido em 27 de fevereiro de 2013. Aceito em 26 de fevereiro de 2014.

\section{Resumo}

John Rawls fundamenta o utilitarismo na concepção de observador ideal presente nas teorias dos sentimentalistas escoceses do século XVIII, particularmente nas teorias de David Hume e Adam Smith. Como a tese do utilitarismo não é tão explícita e acessível na ótica de ambos os filósofos escoceses, pretendemos, no presente trabalho, confrontar a tese do espectador imparcial de Smith e a crítica de Rawls à concepção do observador ideal como fundadora do utilitarismo. Observamos maior abrangência para o espectador imparcial em relação ao observador ideal utilitarista nas escolhas morais.

\section{Palavras-Chave}

Adam Smith. John Rawls. Espectador imparcial. Observador ideal.

\begin{abstract}
John Rawls justifies the utilitarianism on the conception of ideal observer that is present on the theories of $18^{\mathrm{TH}}$ century Scottish sentimentalists, particularly on the theories of David Hume and Adam Smith. As the thesis of utilitarianism is not so explicit and accessible on the views of both Scottish philosophers, we intend, in this paper, to confront the thesis of Smith's impartial spectator and the critique of Rawls on the conception of ideal observer as the foundation of utilitarianism. We observe greater breadth to the impartial spectator in relation to the utilitarian ideal observer in moral choices.
\end{abstract}

\section{Keywords}

Adam Smith. John Rawls. Impartial spectator. Ideal observer.

\section{JEL Classification}

A13. D63. Y80. 


\section{Introdução}

Em comum nas teorias de Adam Smith e John Rawls é a crítica ao domínio do princípio da utilidade nas escolhas morais. Embora Rawls tenha citado o sistema fundado na simpatia e no observador ideal, o sistema dos sentimentos morais elaborado por David Hume e Adam Smith, sistema esse precursor da ideia de imparcialidade que sustenta o utilitarismo clássico, não decorre daí que ambos os filósofos escoceses tenham defendido a tese utilitarista confrontada por Rawls. O utilitarismo que Rawls contesta é a tese que sanciona o princípio da utilidade nas distinções morais, tese moral que decorre mais dos esforços de Bentham, Sidgwick, Edgeworth e Pigou do que de Hume e Smith (Rawls, 1997: 12, 35, 55 e 56; 2000: 81).

A temática que Rawls propõe, ao citar Hume e Smith para comparar a sua tese da justiça como equidade com a tese utilitarista, pretendendo a maior abrangência teórica dos seus princípios de justiça e dos procedimentos para alcançá-lo, superando o princípio da utilidade, é discutir a imparcialidade nas decisões que envolvem grupos de pessoas, ou mais precisamente, como se forma a imparcialidade e perdura no tempo, diante da necessidade de agregação e contratação das preferências individuais. A imparcialidade ad-roga a decisão do grupo, cuja formalização constitui o acordo ou o contrato social que deve ser seguido pelos participantes, tema de suma importância na teoria da justiça de Rawls. Trata-se de apreciar como ocorre a imparcialidade no utilitarismo, e contrapor essa ideia com os procedimentos de justiça na posição original, a qual define a estrutura básica da sociedade bem organizada, tal como expostos na sua teoria da justiça como equidade.

A imparcialidade é um tema moral por excelência. Ser imparcial denota a decisão moral não sustentada unicamente por determinado interesse pessoal, como no caso do egoísmo, nem pelo desejo privado elevado à categoria de princípio moral a ser adotado por todos os outros, como nos casos da tirania e da arrogância. Ser imparcial é adotar uma conduta ou uma ação de concordância social, e não de acordo com algum interesse parcial dos indivíduos. É o procedimento humano presente quando se quer tomar a decisão moral, bem como quando se quer definir a aprovação ou desaprovação, socialmente acordada, de uma conduta ou ação. Portanto, a questão de Rawls procede. Quando se requer que uma sociedade adote um sistema 
decisório, que envolva todos os participantes, convém discutir como se forma e como se mantém a imparcialidade no seio dessa sociedade. Esse é um dos sentidos que Rawls pretende mostrar quando sustenta que as situações postas pela sua teoria da justiça superam a tese utilitarista. Segundo Rawls, os indivíduos, na posição original devidamente caracterizada, adotam os princípios de justiça como decisão moral a ser seguida, o que se contrapõe à incorporação do princípio da utilidade na mente do observador ideal.

Como Rawls encontra a concepção de incorporação de princípios na mente do observador ideal, tal como presente nas teorias dos sentimentalistas escoceses do século XVII e, com muita ênfase, nas teorias de Hume e Smith, e como a tese do utilitarismo não é tão explícita e acessível na ótica de ambos os filósofos escoceses, pretendemos, no presente artigo, abordar o confronto entre a tese do espectador imparcial de Smith e a crítica de Rawls à concepção do observador ideal como fundadora do utilitarismo. A tese do espectador imparcial de Smith, desenvolvida de forma distinta da apresentada por Hume, proporciona esclarecedora percepção da imparcialidade, para além dos temas morais vinculados à finalidade utilitarista de bem-estar social. Observamos, na leitura da obra de Smith, maior abrangência para o espectador imparcial em relação ao observador ideal utilitarista, sugerindo crítica à tese de imparcialidade, tal como posicionada por Rawls.

Em termos práticos, essa investigação, dos argumentos de Rawls acerca do fundamento do utilitarismo no observador ideal, bem como dos ensinamentos de Smith sobre a forma e conteúdo do espectador imparcial, oferece um entendimento sobre como promover a imparcialidade nas escolhas públicas. Veja-se, por exemplo, as implicações para selecionar as políticas públicas que correspondem aos anseios da sociedade. Também são relevantes as apreciações jurídicas e legislativas que são adotadas como paradigmas jurídicos da sociedade. E não menos importante, pode-se citar o mercado como meio ideal para o consenso nos temas econômicos. Em tudo isso, e também em diversos temas próprios das Ciências Sociais, o tema da imparcialidade se revela de suma importância justamente porque se trata de tema moral por excelência, ajudando-nos a distinguir os casos de justiça social, de promoção do bem-estar, de liberdade e de cooperação que são possíveis na sociedade humana. 
Até o presente momento identificamos poucos estudos que tratam especificamente da interpretação de Rawls da teoria moral de Smith (Sugden, 2002, nota 9; Sen, 2003a; Crisp, 2003; Prieto, 2006; Konow, 2006). Na vasta bibliografia sobre cada teoria - dos sentimentos morais de Smith, da justiça como equidade de Rawls e do utilitarismo clássico -, destacamos o trabalho de Amartya Sen, Prêmio Nobel de Economia de 1998, restando muito claro em sua obra a decisiva influência de Smith e Rawls para a sua abordagem das capacitações. Especialmente relevante é o trabalho de Sen no resgate das ideias de Smith, um autor então pouco conhecido, até entre os filósofos morais (Sen, 1999, 2003a: nota 11 e 2010; também esclarecedor, Cerqueira, 2006). ${ }^{1}$ Sendo, portanto, muito ampla a riqueza de ideias desses filósofos, sumarizando nossa metodologia, neste artigo, seguimos principalmente a leitura e interpretação das obras de Smith e Rawls.

Começaremos por Rawls para enfocar a ideia geral de utilitarismo clássico. Na próxima seção, apresentamos nosso entendimento acerca da crítica de Rawls ao utilitarismo, crítica essa sustentada na tese do observador ideal. Na seção seguinte, exploramos a crítica de Smith ao princípio utilitário, e estabelecemos uma compreensão acerca do espectador imparcial. Na terceira seção, confrontamos as duas concepções. Na última seção, situamos temas de debate sobre o problema da imparcialidade nas decisões sociais.

\section{A crítica de John Rawls ao utilitarismo clássico e a tese do observador ideal}

A tese utilitarista, muito comum nas Ciências Humanas, fundamenta as decisões morais no princípio da utilidade: a maximização do bem-estar do indivíduo. Desde a antiguidade greco-romana se debate

${ }^{1}$ Como importante limitação deste estudo, não será abordado o confronto entre a teoria do espectador judicioso de David Hume e a interpretação dada por Rawls (2005: 98-117), o qual envolve o debate sobre a filosofia moral desenvolvida no Tratado da Natureza Humana de Hume (2000). Contudo, pelo menos até onde pudemos apurar, o espectador imparcial de Smith amplia a compreensão das aprovações e desaprovações morais para temas distintos da justiça como virtude construída artificialmente pela sociedade, tal como defendida por Hume (2000: Livro 3, Parte 2, Seção 1). Além disso, Hume aderiu inteiramente ao princípio da utilidade na sua obra posterior (Hume, 1995), esse sistema então explicitamente objetado por Smith (1999: Quarta Parte).

Estud. Econ., São Paulo, vol.45, n.1, p. 185-214, jan.-mar. 2015 
se o propósito da vida é a eudaimonia - a felicidade e o bem-estar. $\mathrm{Na}$ doutrina do eudemonismo são moralmente boas as condutas que levam à felicidade. Para Jeremy Bentham e John Stuart Mill, uma ação humana é certa se tende a promover felicidade do próprio indivíduo e de todos os afetados pela ação e, ao contrário, é errada se produzir o inverso da felicidade. Este seria o conceito de utilitarismo do ato (act utilitarianism). Existem outras versões modernas: utilitarismo da regra (rule utilitarianism), a generalização utilitária, o utilitarismo de motivo e o utilitarismo cooperativo. E existem, mais ainda, estudos refutando o utilitarismo (Frey, 1996). Essa ampla influência nas Ciências Humanas revela a atual complexidade do termo "utilitarismo", dificultando a conceituação precisa.

Entendemos que Amartya Sen (1999) bem delimita o utilitarismo em três requisitos: consequencialismo, bem-estar e maximização. Sen resume os dois últimos quesitos como representativos do utilitarismo de resultado. O que se tem é a ênfase exclusiva para o resultado ou a consequência das condutas e ações morais. Tal visão combina com a doutrina do eudemonismo em buscar uma finalidade para a vida, esteja essa finalidade fixada ora na felicidade, ora no bem-estar, ora, como se sustenta na atualidade, na satisfação dos desejos ou preferências. Para os nossos propósitos, essa concepção de resultados do utilitarismo permite compreender as formulações subsequentes de Rawls e Smith.

Perceba-se como a tese utilitarista atrai a fundamentação moral. Ela nos convida a refletir sobre o projeto de vida, sobre qual seria o objetivo da vida, e a levar em consideração os objetos, os fatos empíricos, em suma, a empiria que proporciona melhoria no futuro bem-estar, acalmando o compreensivo desejo por aumentar o grau de felicidade ou prazer e repelir as situações que trazem tristeza ou dor (tese de Bentham). Assim, é útil para a vida humana seguir as ações e condutas que visam os objetos que proporcionam o bem-estar, de modo que o exercício dessa conduta útil pelos membros da sociedade, ou pela maioria, ou na média, conduz a sociedade para o melhor bem -estar possível ou para a maximização do bem-estar. 
Para situar o confronto com o utilitarismo, John Rawls (1997:25) ${ }^{2}$ parte do principio da utilidade de Sidgwick como sendo o mais claro e compreensível para o embate: "a ordenação da sociedade é correta, e em decorrência, justa, se as instituições representativas são conduzidas para obter o maior saldo líquido de satisfação obtido na soma das participações de todos os indivíduos". Tal proposta do utilitarismo implica estruturar a sociedade, suas normas e instituições, de maneira que o objeto escolhido, o que proporciona o bem-estar, deve ser procedido, formalizado, não só na eleição do tipo de objeto fixado, mas também planejando que esse objeto atinja o maior saldo líquido de satisfação, ou nas palavras da Ciência Econômica, produza a eficiência do sistema. Rawls alerta para esse caráter procedimental do utilitarismo, para poder compará-lo com o procedimento de obtenção dos dois princípios de justiça composto na sua teoria da justiça como equidade.

Rawls (1997: 26 e 27) destaca que, no utilitarismo, o sumo bem é estabelecido, no caso, no saldo total de satisfação. Os sistemas morais teleológicos, que visam um fim, como o utilitarismo, tornam-se de simples compreensão. Especifica-se o bem, ou nas virtudes humanas (perfeccionismo), ou no prazer (hedonismo), ou na felicidade (eudemonismo), ou na satisfação dos desejos (utilitarismo clássico). O passo seguinte é firmar a ideia de maximização do bem como um ato racional. Isso colabora para compreender como todos concordam que ganhar a vida consiste em maximizar o bem - virtudes, felicidade, satisfação de desejos. Todas as decisões morais serão guiadas por esse projeto de vida imposto para toda a sociedade.

2 Na nota 9, do Capítulo I, da Teoria da Justiça, Rawls (1997: 659-660) faz referência à obra de Henry Sdgwick, The Method of Ethics (1907), como síntese da tese utilitarista. Considera que o Livro III de seu Principles of Political Economy (1883) aplica essa tese em questões de justiça econômica e social, antecipando a obra de A. C. Pigou, The Economics of Welfare (1920). A obra de Sidgwick, Outline of the History of Ethics (1902), aborda a história da tese utilitarista. Ainda segundo Rawls, ela começa com An Inquiry Concerning Virtue and Merit (1711), de Francis Hutcheson, que contém o primeiro princípio da utilidade: "melhoré aquela ação que produz a maior felicidade para o maior número [de pessoas]; e pior é aquela que, de igual maneira, ocasiona a miséria". Em seguida Rawls acrescenta: "outros trabalhos importantes do século XVIII são as obras de Hume, A Treatise of Human Nature (1739) e An Inquiry Concerning the Principles of Morals (1751); a obra de Adam Smith, $A$ Theory of the Moral Sentiments (1759); e a de Bentham, The Principles of Morals and Legislation (1789). A essas obras devemos acrescentar os escritos de J. S. Mill representados por Utilitarianism (1863) e de F. Y. Edgeworth, Mathematical Psychics (Londres, 1888)".

Estud. Econ., São Paulo, vol.45, n.1, p. 185-214, jan.-mar. 2015 
Tanto John Rawls (1997) quanto Amartya Sen (1979, 1985, 1999, 2003b, 2009) criticam essa forma de utilitarismo por conduzir à irrelevância a distribuição das condições para acessar o bem-estar. O utilitarismo tangencia a análise dos processos necessários para se atingir uma sociedade justa e igualitária mediante o procedimento de apoiar o aumento do saldo líquido das satisfações. Para Rawls (1997) e Sen (2003b), as condições das pessoas são relevantes para se pensar na distribuição justa dos bens, o que deveria anteceder o cálculo utilitarista. Para Rawls (2008), na soma obrigatória do procedimento utilitarista, o conceito de justo perde relevância para o conceito de bem.

Na sua visão de bem-estar, Rawls (1997) não se limita a um único princípio geral, como o fazem utilitaristas como Bentham (1988) e Harsanyi (1955); considera diferentes bens primários desde a renda monetária até a liberdade. Além disso, o indivíduo Rawlsiano embora tenha algum projeto de vida racional não conhece os pormenores - objetivos e interesses - desse projeto. Ou seja, tal indivíduo está mais para o conceito de razoabilidade do que para o conceito de racionalidade munida de informações perfeitas como apregoado pelo utilitarismo. Outra questão-chave na obra de Rawls (1997, 1974) que o diferencia dos autores utilitaristas é que ele apresenta o chamado "princípio da diferença" [ou critério maximin] de justiça social que prioriza os interesses das pessoas em pior situação dentro da coletividade.

Conforme Sen (1999), o grande erro da análise utilitarista é não ter a capacidade de fazer comparações interpessoais, uma vez que embasa sua análise nas escolhas em separado de cada indivíduo. Além disso, o cálculo utilitarista da soma e agregação de todas as utilidades - com o objetivo de escolher a alternativa que maximize a utilidade e, consequentemente, a satisfação de uma sociedade - pode ser injusto em relação àqueles que aprenderam a se conformar com seu estado de privação, dada a necessidade de sobrevivência.

Utilitaristas como Harsanyi (1955), por exemplo, afirmam que o utilitarismo tem como objetivo prover a igualdade de tratamento aos interesses de todos os indivíduos (universabilidade de tratamento dos agentes). A crítica de Sen (1979) é que, se por acaso os seres humanos fossem idênticos, e pudessem ser agrupados - todos - dentro de uma função de utilidade social, a aplicação do princípio prévio 
de universabilidade de tratamento, "dando assim um peso igual aos interesses iguais de todas as partes", as análises sociais se tornariam muito mais simples, uma vez que a igualdade de utilidades marginais de todas as pessoas coincidiria com a igualdade da utilidade total da sociedade.

Outro problema para Sen $(1979,1985)$ é que, tradicionalmente, os utilitaristas na impossibilidade de analisar diretamente a utilidade a representam como um estado mental, por exemplo, a satisfação de desejos [felicidade], que por sua vez é obtida por intermédio da renda. Esta representação da utilidade não leva em conta a diversidade dos agentes que formam o tecido social em converter renda em satisfação de desejos. Além disso, uma vez que o utilitarista parte do principio de universabilidade, uma pessoa com uma patogenia, qualquer que fosse ela, receberia o mesmo tratamento de uma pessoa sadia, embora, ceteris paribus, a primeira apresente condições menores de converter a mesma quantidade de renda em "utilidade" em comparação com a segunda.

Como diz Rawls (1997: 28), a empiria colabora para atestar o procedimento utilitarista. Em estágios avançados da sociedade acontecem, de fato, situações em que o saldo social de utilidade aumenta, e se admite que seja aceitável compensar as perdas com ganhos maiores, ou violar liberdades para atingir um bem maior à disposição de todos. Pouco se apresentam situações em que a distribuição dos bens precisa ser debatida. Faltam evidências que incitariam a preocupação do utilitarista com a partilha justa dos bens.

As condições de fato são favoráveis para a defesa do apelo utilitarista, tornando-se apoio para as decorrentes análises nas Ciências Humanas e Sociais com caráter empírico. A maximização do objeto é matematizável, permitindo avançar um vasto campo de conhecimento nas Ciências Econômicas, também sustentável em outras teorias das áreas Humanas e Sociais, quando o objeto a ser maximizado é dirigido à felicidade, satisfação e bem-estar. É justamente por essa ampla influência empírica que se torna obrigatória a crítica à tese utilitarista, como fazem Smith, Rawls e Sen.

Voltando exclusivamente para a crítica de Rawls, convém, agora, explicitar em linhas gerais a sua teoria da Justiça como Equidade. Rawls nos convida para um status quo apropriado, denominado de 
posição original, a partir da qual os dois princípios de justiça, que guiam a sociedade bem organizada, são escolhidos. Trata-se de uma situação de contrato (acordo original), constitutivo da sociedade, fiel à tradição contratualista de se estabelecer um ponto racional de partida, e que deve ser pensado na sua mais alta expressão e abrangência. É também por esse mesmo motivo que o caráter de princípio às duas regras propostas por Rawls - os dois princípios de justiça -, seriam adotados para manter a sociedade bem organizada.

O original proposto por Rawls não constitui um estado histórico, um estado inicial da sociedade, tal como sugere o estado de natureza de Hobbes (1997, 1 $1^{\text {a }}$ Parte, Cap. XIII), mas original no âmbito da reflexão racional. A posição original tem que ser instaurada no tribunal da razão, no sentido de que aí tem que se dar o acordo racional. Se os participantes se colocam nessa posição original, e pensam dessa perspectiva, então os dois princípios de justiça serão os escolhidos para ordenar a sociedade.

O primeiro princípio proposto por Rawls dá primazia ao justo - ao mesmo direito para todos, ficando para o momento seguinte, a partir do segundo princípio, apreciar os múltiplos casos de distribuição dos bens, com igualdade de oportunidades e obedecendo ao princípio da diferença:

i) Cada pessoa tem o mesmo direito irrevogável a um esquema plenamente adequado de liberdades básicas iguais que seja compatível com o mesmo esquema de liberdade para todos; e

ii) As desigualdades sociais e econômicas devem satisfazer duas condições: primeiro, devem estar vinculadas a cargos e posições acessíveis a todos em condições de igualdade equitativa de oportunidades; e, em segundo lugar, têm de beneficiar ao máximo os membros menos favorecidos da sociedade (o princípio da diferença).

Nota 3: (...) continuo empregando o termo "princípio da diferença" para enfatizar, primeiro, que esse princípio e a regra maximin de decisão em condições de incerteza (§ 28.1) são duas coisas bem distintas; e, em segundo lugar, que ao preferir o princípio da diferença a outros princípios distributivos (por exemplo, um princípio de utilidade (média), que inclua um mínimo social), não se lança mão da regra maximin para decisão em condições de incerteza (...) (Rawls, 2003: 60). 
Contudo, Rawls (2003: 21) reconhece um obstáculo nas condições iniciais, comum em qualquer concepção política de justiça que emprega a ideia de contrato social, relacionada ao ponto de vista a partir do qual os participantes concordam com os dois princípios de justiça. Aqui, Rawls realça crucial restrição ao conhecimento dos participantes com o denominado "véu de ignorância".

$\mathrm{Na}$ posição original, não se permite que as partes conheçam as posições sociais ou as doutrinas abrangentes específicas das pessoas que elas representam. As partes também ignoram a raça e grupo étnico, sexo, ou outros dons naturais como a força e a inteligência das pessoas. Expressamos figurativamente esses limites de informação dizendo que as partes se encontram por trás de um véu de ignorância. (Rawls, 2003: 60-1).

O que se pretende é garantir que os princípios de justiça sejam referendados por cidadãos livres e iguais, informados e racionais, mantendo a condição igualitária desde o início, originando o nome justiça como equidade. O procedimento é caracterizar a posição original, hipotética e não vinculada ao estágio histórico, e ponderar nesse ponto de vista as condições de distribuição justa ou equitativa. Nesse exercício de ponderação racional, devem ser abandonadas as posições sociais e as doutrinas morais abrangentes preferidas pelas partes, parcialidades essas que desviam o foco do igualitarismo do primeiro princípio de justiça. Se somos ricos, ou pobres, não podemos esperar que todos os outros aceitem uma estrutura básica que favoreça os ricos, ou os pobres, simplesmente por essa razão (Rawls, 2003: 25)

O que seriam cidadãos livres e iguais, informados e racionais, sociedade bem organizada, livre e igualitária, e notadamente as condições da posição original, permeia grande parte da Teoria da Justiça, o que estenderia demais essa exposição. Rawls não se filiou apenas ao caráter procedimental da teoria, nessa ordem, exposição da posição original, escolha dos dois princípios de justiça e justiça procedimental pura. Rawls também recorreu ao senso de justiça (Rawls, 1963), bem como às virtudes judiciais, entre as quais a imparcialidade e a prudência, oriundas da capacidade de razão (teórica e prática) 
(Rawls, 2002). ${ }^{3}$ Entretanto, com o procedimento que Rawls (2003: 40-44) denomina de equilíbrio reflexivo, do senso moral retorna-se a ideia de posição original e das restrições impostas pelo véu de ignorância, pois, se adotadas, garantem a reflexão racional e ponderada acerca dos princípios de justiça da estrutura básica e das demais regras decorrentes.

Assim, por um lado Rawls recorre ao racionalismo vigente em determinada situação sociocultural, a situação da sociedade democrática e bem organizada, na qual é perfeitamente reconhecível a ampla adesão aos dois princípios de justiça, com afastamento das visões parciais e conflitos por posições sociais e doutrinas divergentes por meio do véu de ignorância, parcialidades essas que porventura possam ser trazidos para a posição inicial, as quais desestabilizam a democracia constitucional pretendida. Por outro lado, Rawls fundamenta esse racionalismo na concepção kantiana, admitindo a presença do senso de justiça, desde que também ligado à psicologia inspirada no racionalismo kantiano.

O que devemos reter, por ora, no amplo debate que se abre nesses dois lados, é que a imparcialidade nas decisões judiciais, para Rawls, decorre, portanto, da reflexão racional na posição original, sujeita à restrição do véu de ignorância.

Somando-se às outras condições da posição original, o véu de ignorância elimina possíveis diferenças no que diz respeito a situações privilegiadas de negociação, de tal forma que em relação a isso e a outros aspectos as partes encontram-se simetricamente situadas. Os cidadãos estão representados apenas como pessoas livres e iguais: pessoas com um grau mínimo suficiente das duas faculdades morais e de outras capacidades que lhes permitem ser membros cooperativos normais da sociedade a vida toda. Ao situar as partes simetricamente,

3 Rawls (1963) suscita o senso de justiça, a partir da abordagem psicológica de Piaget (o sentimento de culpa), em três estágios: culpa oriunda da autoridade; culpa proveniente da associação; e culpa com os princípios, nessa ordem, enfatizando o último estágio na sua concepção da teoria da justiça. Rawls (2002) trata da diferença entre razoável e racional na oposição do construtivismo kantiano na teoria moral, em conferências de 1980. E em toda a Terceira Parte da Teoria da Justiça, Rawls (1997) considera a influência das virtudes e dos sentimentos que servem para reunir as pessoas e determinar a moralidade como doutrina abrangente. 
a posição original respeita o preceito básico da igualdade formal, ou o princípio da equidade de Sidgwick: aqueles que forem semelhantes em todos os aspectos relevantes devem ser tratados de maneira similar. Uma vez satisfeito esse preceito, a posição original é equitativa (Rawls, 2003: 122-3).

Para objetar a posição original, Rawls (2003: 116) suscita a possibilidade de incluir hipóteses psicológicas ou condições sociais que não foram previstas, ou seja, adentrar no lado que examina o que seria o senso de justiça. Sem considerar teses psicológicas ou sociais, que diferem das estabelecidas para a posição original, Rawls (2003: 117) entende que não há como escolher outros princípios distintos dos dois princípios de justiça (por exemplo, os princípios libertarianos de Buchanan, Gauthier e Nozick, ou o princípio da utilidade média, conforme Rawls, 2003, 22n16 e 135).

Dessa espécie de novas condições para a posição original são as ideias do observador ideal e da ênfase na solidariedade, tais como as difundidas por Hume e Smith (Rawls, 1997: 201). Essas condições, segundo Rawls, sancionam a escolha do princípio da utilidade como organizador da sociedade. Com essas duas concepções, diz Rawls (1997: 29), a soma se faz: o princípio de um indivíduo se aplica à sociedade e "muitas pessoas se fundem numa só". Nesse interessante contraponto entre a teoria da justiça como equidade e o utilitarismo seguimos agora a argumentação de Rawls.

Para Rawls, o espectador é "observador ideal", "idealmente racional e imparcial que ocupa um ponto de vista geral e possui todo o conhecimento pertinente das circunstâncias" (1997: 201). Como reconhece Rawls, essa definição não se opõe a sua teoria, pois a decisão do observador ideal pode ser a mesma da posição inicial. Isso porque a definição não especifica a psicologia do observador ideal. A definição de observador ideal, tal como formulada,

... se destina a isolar certos traços centrais característicos da discussão moral, o fato de que tentemos apelar para os nossos juízos ponderados após uma reflexão conscienciosa, e coisas afins. A definição contratualista vai mais 
além: tenta fornecer uma base dedutiva para os princípios que explicam esses julgamentos. Pretende-se que as condições da situação inicial e a motivação das partes formulem as premissas necessárias para que se atinja esse objetivo (Rawls, 1997: 202).

O observador ideal é aquele que aprova a instituição "de forma mais veemente" que outra similar, pois detém amplo conhecimento da situação, momento que dá prazer ao contemplar o sistema social perfeito. Esse prazer decorre da compreensão da situação dos outros (Rawls, 1997: 202). Por isso que aqui se relaciona "a porção equivalente ao saldo líquido de prazer sentido pelos que são afetados por ele" à convicção do observador ideal. Assim se filia o princípio da utilidade ao observador ideal, ou seja, na necessidade de se aprovar as condutas e ações segundo a percepção do saldo líquido das satisfações para a perfeição do sistema social. Rawls destaca o cálculo utilitário, isto é, a compensação entre sofrimentos e prazeres dos outros na imaginação do observador ideal, mas também a necessidade de contemplação do sistema como o bem a ser atingido.

A contraposição é aguda: enquanto o observador ideal detém amplo conhecimento da sua e da situação social dos outros, os sujeitos na posição inicial estão desinteressados dessa situação via véu de ignorância. Um indivíduo dotado do poder do observador ideal sugere a sua visão particular, como a visão a ser seguida pelos outros, o que torna as suas aprovações o padrão de justiça. Tal procedimento representa a "fusão de desejos" em um único desejo, o que significa impessoalidade, e não imparcialidade (Rawls, 1997: 204).

A fusão é compreendida como o cálculo utilitarista, ou seja, a ponderação de prazeres e sofrimentos. O problema é como ocorre essa fusão na mente do observador ideal. Segundo Rawls (1997: 673), essa questão não foi claramente formulada, mas poderia ser compreendida na seguinte expressão de Edgeworth:

Assim como os movimentos de cada partícula, confinada ou solta, em um cosmo material, estão continuamente subordinados a uma única soma total máxima de energia acumulada, também os movimentos de cada alma, seja 
egoisticamente isolada ou ligada pela simpatia, podem estar realizando a máxima energia do prazer, o amor Divino do universo (Edgeworth, F. Y. Mathematical Physics: 12 apud Rawls, 1997: 673).

Um padrão de bem-estar assim sancionado, no cálculo utilitarista do observador ideal, não precisa ser adotado na posição original. A não ser que todos os participantes fossem altruístas perfeitos, no sentido de desejarem o maior saldo líquido de felicidade, se essa posição fosse compatível com a do observador ideal. Porém, não há conflitos morais entre altruístas perfeitos e nem problema de justiça. É necessário haver o conflito para gerar a situação de justiça. Segundo Rawls (1997: 205), o desinteresse mútuo na posição original proporciona esse conflito, na necessidade dos litigantes escolherem os princípios de justiça em uma posição original de igualdade, de decidirem os princípios regulatórios das reinvindicações mútuas e aqueles indivíduos que serão os representantes desse acordo. O utilitarismo não possui esse mecanismo de assegurar a imparcialidade; confia na capacidade de fusão dos desejos em única mente, na do observador ideal, caracterizando a impessoalidade.

Rawls (1997) utiliza a ideia de benevolência, como virtude a ser seguida, na contraposição entre os mecanismos de agregação social. $\mathrm{O}$ problema do utilitarismo consiste em decidir qual a posição de bem - estar seria a escolhida. Diante das distintas concepções de bem e de felicidade entre os indivíduos, não há resposta única para uma situação de bem-estar decidida no âmbito do observador ideal. Faltam critérios para se decidir quando ocorrem os conflitos, quando as visões distintas de felicidade são contrapostas. Por isso a importância de se estabelecer os dois princípios de justiça, antes de se guiar pelo princípio da utilidade.

Portanto, um amor pela humanidade que deseja preservar a distinção entre as pessoas, reconhecer o caráter isolado da vida e da experiência de cada um, fará uso dos dois princípios da justiça para determinar os seus objetivos quando os vários bens valorizados estão em oposição. Isso equivale simplesmente a dizer que esse amor é guiado pelo que os próprios indivíduos 
aceitariam em uma situação inicial justa que lhes assegura uma representação igual como pessoas éticas (Rawls, 1997: 207).

Rawls reforça a primazia do justo sobre o bem, bem como o poder de fundamentar o justo na posição original. As suposições do observador ideal, do perfeito altruísta e da benevolência universal, em nada afetam essa concepção inicial do justo, sendo decorrentes quando se trata de observar a distribuição desses bens. A suposição da posição original de Rawls não impede definir as virtudes morais ou a discussão dos sentimentos morais de ordem superior. A contraposição se refere ao mecanismo para se efetuar os acordos, entre o observador ideal e a posição original, sendo que o primeiro privilegia o bem, em detrimento do justo, virtude essa predominante na teoria contratualista de Rawls.

Convém destacar, por fim, que para Rawls (1997: 35), Hume não é utilitarista, não servindo aos seus propósitos de crítica. O que Rawls extrai de Hume é a tese de necessária concordância acerca do útil ou agradável para todos, que apoia a ideia do observador ideal. Rawls reconhece que são diferentes o espectador imparcial de Smith e o espectador judicioso de Hume, já que o primeiro é usado "for a somewhat different idea" (Rawls, 2000: 81). No entanto, não encontramos em Rawls o desenvolvimento claro dessa diferenciação. Esse é o momento, então, de analisarmos a concepção de Adam Smith, como segue na próxima seção.

\section{A crítica de Adam Smith ao princípio da utilidade e a tese do espectador imparcial}

A ética de Smith é fundada na simpatia com o sentido de compartilhar afetos, emoções ou sentimentos. No entanto, o que distingue Smith de Hume é o fato de que compartilhar afetos não significa apenas acompanhar o prazer que o espectador sente ao reconhecer a beleza do sistema. Hutcheson e Hume se preocuparam mais com a finalidade dos afetos do que com as causas, fundamentan- 
do o julgamento moral em considerações de estética: moral beauty (Smith, 1999: 18; Darwall, 1999). Smith se diferencia de Francis Hutcheson, seu professor de Filosofia Moral, e de seu amigo Hume, pois, para ele, o julgamento moral provém mais do senso de conveniência do que do senso de beleza do sistema. O que Smith denomina de senso de conveniência constitui o despertar para a análise dos motivos das ações e condutas. O ato é moralmente um bem ou um mal dependendo mais do sentimento que o motivou do que do efeito por ele produzido: depende mais da conveniência percebida no compartilhar emoções, do que do mérito ou demérito das ações e condutas.

Seja, por exemplo, o caso de um cientista profundo conhecedor de sua matéria. Aprovamos o julgamento do cientista se estiver conforme a razão, ou nos termos de Smith, conforme a verdade e a realidade. A utilidade social da opinião acerca dos resultados aumenta o valor do cientista para a comunidade. Mas, até agora, não foi definida a aprovação moral do que foi dito pelo cientista. Se a exposição trata de objetos que não têm relação conosco ou com as pessoas que estamos julgando, há pouco perigo de brigas ou intrigas, em caso de discordâncias. O debate se concentra na capacidade de bom gosto e discernimento, e não na atitude moral das pessoas. Diferente é o caso em que os objetos afetam ou influenciam a nós e ao nosso modo de vida. Agora, clamamos por solidariedade, companheirismo e correspondência de sentimentos, e desprezamos a indiferença, o individualismo, a insensibilidade e falta de sentimentos. É aqui que os espectadores morais devem se esforçar para adotar o sentimento da pessoa que age. Esta pessoa também deve se esforçar para adequar o grau de sua paixão até um limite que possa ser adotada com mais facilidade pelos espectadores. Um pretende acompanhar o que o outro parece sentir, e o outro tenta conter seus sentimentos num grau que possam ser simpatizados pelo espectador ordinário. É o compartilhar emoções, no aqui e agora, em duas vias, que caracteriza o que Smith denomina de simpatia: a solidariedade com qualquer paixão (Smith, 1999: 8).

Smith (1999: IV, i) reconhece que a utilidade exerce ampla influência no prazer que sentem os agentes e os espectadores quando contemplam sistemas bem engendrados. Esse é o princípio que recomenda a criação e manutenção de instituições voltadas para o interesse público, e promove o debate político, comercial e produtivo. Smith 
sugere persuadir o governante expondo a harmonia e a suavidade com que pode rodar a máquina de governo, se implantadas as medidas recomendadas, causando impacto estético. Essa é a mesma orientação de Hume, destacada por Rawls, já que a contemplação do sistema que agrada define a utilidade dos objetos que o compõem.

Hume (1995: IX; 2009) considerou que as ações virtuosas são aquelas que são úteis ou agradáveis, seja para a própria pessoa, seja para a outra pessoa. Todavia, essa utilidade não pode ser a fonte principal da aprovação ou desaprovação moral das ações e condutas; os sentimentos são distintos, entre o compartilhar afetos e o contemplar sistemas funcionais, e principalmente porque o senso de conveniência é distinto da percepção de utilidade (Smith, 1999: 230, 231). A ideia de utilidade é refinada no pensamento smithiano. Contemplar o bom funcionamento das instituições, a ordem do sistema, sentir prazer nessa contemplação, não constitui o elemento essencial para a aprovação da conduta. O senso de conveniência supera essa restrição estética da utilidade e oferece outros elementos para o julgamento moral.

Quando se trata de examinar questões da mecânica social, funcionamento de instituições, adequação da legislação e cálculo de medidas quantitativas e qualitativas, pode ser adotado o princípio da utilidade, quando então se avalia a beleza estética do sistema (Smith, 1999: 106, 107). Mas quando se trata de examinar as interações morais, as questões supremas de justiça e de regras gerais de condutas, cabe primordialmente o exame da conveniência das ações conduzido na ótica do espectador imparcial.

Seguindo o princípio da utilidade, deixamos de consumir algo no presente, posto que o objeto remoto traga muito provavelmente maior prazer no futuro. Cultua-se o objeto remoto. Entretanto, na Ética de Smith, a abstenção do prazer presente representa a prática do autodomínio (Smith, 1999: VI, iii), uma ação julgada apropriada, ordenando a aprovação segundo o senso de conveniência, mais do que a consideração utilitária pelo objeto remoto. Quem age com autodomínio, merece a estima e aprovação de todas as pessoas (Smith, 1999: 328), independentemente do objeto perseguido. Quem age preferindo o prazer futuro com o objeto remoto aparenta apenas bom gosto e discernimento, beleza que pode se esvair na futilidade do objeto de desejo. 
O mandamento moral relevante nesse caso, segundo Smith, é a virtude do autodomínio, cujo aperfeiçoamento ao longo da vida detém os impulsos em direção aos objetos que causam prazer e, contrariamente, aos que causam dor.

O sentimento de aprovação a partir da utilidade não exige a concordância dos sentimentos alheios (Smith, 1999: 235). O egoísta solitário, sem contato com os outros, também pode considerar suas ações agradáveis ou desagradáveis. Pode ver uma beleza na prudência da sua conduta. Pode transferir um prazer presente por um suposto maior prazer no futuro. São questões de gostos pessoais que se amoldam ao tipo egoísta, enaltecido em interpretações apressadas na teoria econômica. ${ }^{4}$ Contudo, quando esse indivíduo se defronta com os outros, experimenta sentimentos compartilhados, simpatiza com as emoções alheias, tem ressentimentos com as situações de conflito e quer que as suas afeições sejam alvo de simpatia. Então busca o grau de compartilhamento de emoções possível na situação, conhecimento esse que permite ao agente compreender com mais ênfase porque as suas ações finais mereceriam a justa recompensa ou castigo, mérito ou demérito, aplauso ou condenação.

Para Smith (1999: 379 e 380), o sistema moral que reduz a virtude à utilidade é absorvido pelo sistema da conveniência. Isso porque o caráter agradável ou útil precisa ser graduado segundo a conveniência da ação. Esse sistema, segundo Smith, precisa definir, não a utilidade do caráter, mas o grau apropriado, porque um afeto é moralmente útil se confinado a certo grau de moderação. A medida original desse grau apropriado até pode ser avaliada pela utilidade média, porém ainda permanece o cálculo do prazer sentido com a beleza do sistema, agora transferido para o sujeito ideal, ou o observador ideal de Rawls, mantendo o distanciamento da avaliação ética da situação. Smith acrescenta o afeto correspondente do espectador, a graduação dos sentimentos vigiada pelo espectador imparcial, aperfeiçoando a explicação das ações e condutas morais. Os julgamentos estritamente

4 Este entendimento de que, na filosofia moral de Smith, o ser humano simpático é altruísta ou benevolente, enquanto que, nos fundamentos econômicos, o princípio do interesse próprio mostra um indivíduo egoísta, foi suscitado por pensadores da Escola Histórica Alemã e ficou conhecido como o Das Adam Smith Problem. Este debate tem mobilizado diversos pensadores. O debate se estende para a verificação de compatibilidade ou não das obras de Smith (Bianchi, 1988: 104 e 135; Ganem: 1999). Heilbroner (1982: 439) lembra que este problema, se o ser humano é egoísta ou altruísta em suas relações interpessoais, não é só de Adam Smith: é de todas as pessoas. Raphael (1992: 116) diz que esta tensão não é um problema de Smith; é da vida real. 
utilitaristas, por se vincularem à estética, são secundários na ética smithiana.

Até aqui não se visualiza discordância importante entre a teoria de Smith e a crítica de Rawls ao utilitarismo clássico. A associação do princípio da utilidade à beleza sistêmica e às consequências das ações também é criticada por Rawls como limitador ao exercício do senso de justiça e da capacidade racional na posição original. Por isso a questão deve se voltar para o mecanismo de agregação proporcionada pelo espectador imparcial, ou, nos termos smithianos, para a graduação do senso de conveniência.

A graduação dos dois diferentes esforços, as tentativas dos espectadores de se solidarizarem com as paixões da pessoa afetada, e os empenhos desta em rebaixar suas emoções para que possam ser acompanhadas, resultam as atitudes de sentir muito pelos outros e pouco por nós mesmos, as quais conduzem à perfeição da natureza humana, à harmonia de sentimentos e paixões. É nesse imenso esforço humano de partilhar emoções que Smith (1999: I, i, v) introduz a figura do espectador, posto que esse mecanismo conceda aquele tom de moderação entre os dois mencionados esforços. ${ }^{5}$

Note-se que Smith claramente se refere a uma mudança de atitude da própria pessoa, uma moderação das paixões e um esforço para compreender as paixões dos outros, na medida certa para compartilhar, para ser compreendido, algo que, dependendo das paixões, nem sempre é passível de controle, ultrapassando o ânimo normal do espectador. Ai então, quando conflita com o interesse próprio, a pessoa deve examinar cada situação em particular, como se estivesse fora de si, como se não fosse ela mesma, como se fosse espectadora de si, suspendendo as suas paixões egoístas, considerando as opiniões dos outros, controlando as suas emoções, principalmente as do excesso de amor por si, adequando os seus sentimentos para que possam ser acompanhados pelos outros, imaginando o que os outros julgam a respeito da ação ou conduta.

\footnotetext{
5 Tugendhat (2000: 315) destaca esse ponto da Ética smithiana da conveniência por proporcionar, pela primeira vez na história das ideias morais, um sentido coerente para a expressão "meio-termo" da Ética aristotélica, o que não é pouco em termos do que implica para uma teorização moral.
} 
O senso de conveniência é especialmente vigoroso contra o excesso de amor de si: o egoísmo psicológico. Esse é momento regulador do espectador imparcial - o juiz interno (Smith, 1999: I, i, 5.5). O espectador imparcial, o juiz de todas as condutas, mostra que não somos os únicos nesse mundo, que nossas paixões devem se compatibilizar com as dos outros que nos cercam. O espectador imparcial é como se fosse a consciência de cada um, que atua sobre a pessoa, avaliando a conduta da própria pessoa e as circunstâncias que envolvem as outras pessoas, formando um juízo, o caráter moral, como se visse em ação moral num espelho que reflete a si mesmo no convívio com as outras pessoas. Além da natural disposição por compartilhar emoções - a simpatia, Smith conjetura que o cuidar de si mesmo é adequado e correto, como já disseram os estóicos. Porém, a sociedade oferece o espelho para ajustar o nosso caráter privado à convivência social (Smith, 1999: III, i).

Aqui, como em todos os outros casos, devemos nos ver não tanto sob a luz em que naturalmente nos mostramos a nós mesmos, mas sob a luz em que naturalmente nos mostramos aos outros. (...) Ainda que seja verdadeiro, portanto, que todo indivíduo, em seu próprio peito, naturalmente prefere a si mesmo a todos os outros homens, ninguém ousa olhar os outros de frente e declarar que age segundo esse princípio. (...) Se agisse de modo que o espectador imparcial pudesse compartilhar os princípios de sua conduta, o que é, entre todas as coisas, a que mais deseja ver realizada, deveria nessa e em todas as outras ocasiões, tornar humilde a arrogância de seu amor de si, reduzindo-o a algo que os outros possam aceitar (Smith, 1999: 103. Grifamos).

O espectador imparcial se apresenta para o exame e julgamento da própria conduta, em cada situação de compartilhar afetos. Na condição de arguto observador, obriga-se a analisar a situação também com os olhos das outras pessoas (Smith, 1999: 143). É por isso que a imaginação do suposto espectador imparcial alcança a vivência social experimentada pela própria pessoa, especialmente àquelas situações em 
confronto com as visões dos outros, quando há necessidade de dosar as paixões sentidas. O espectador imparcial não aparece na teoria de Smith como modelo de racionalidade, tampouco como a consciência capaz de deter todo o conhecimento dos diversos aprendizados morais. Não é sequer o observador ideal que contempla unicamente o prazer obtido com as satisfações dos desejos. O espectador imparcial constitui a percepção geral da necessidade de partilhar afetos, especialmente o de reduzir o excesso de amor de si, para obter a justa aprovação das condutas, em cada situação, em cada momento, sendo moldado a cada situação vivenciada.

O julgamento do espectador imparcial proposto por Smith é circunstancial, contingente; ocorre a todo o momento, notadamente na presença de conflitos morais, ocasião para considerar o justo. Requer uma perspectiva geral, como se olhasse do alto todo o teatro moral. Essa perspectiva não se fixa exclusiva e necessariamente no prazer contemplativo da beleza das cenas. Como diferencia Smith, é mais decisivo fazer reflexão acerca dos motivos presentes nas ações, do que se guiar pelos variáveis e múltiplos resultados, previstos ou atingidos, os quais sustentam as éticas consequencialistas, tal como a da tese utilitarista.

O senso de conveniência é sentimento natural humano evidenciado pela apreciação dos motivos das condutas. Contudo, o olhar diferenciado do espectador requer reflexão. Smith, nesse sentido, adota a filosofia de Hume: trata-se do uso da razão segundo o hábito e a experiência. Por indução, experimentando o compartilhar sensações ao longo da vida (do senso de conveniência), o espectador da própria pessoa forma os seus padrões sobre como agir e se conduzir. Porém, mesmo que esses padrões sejam imediatamente reconhecidos pelo juiz interior, sendo usados nas aprovações e desaprovações seguintes de condutas, eles não escapam de reexame nos conflitos, o que representa a vigilância exercida pelo espectador imparcial, quando surge a necessidade do exercício da simpatia nas duas vias, rebaixando as ações egoístas e se esforçando para distinguir o sentimento dos outros.

Assim, não é o poder da humanidade ou da benevolência universal que determinam o sacrifício dos interesses próprios, não é o prazer sentido com o que é útil ou agradável: "é a razão, o princípio, a consciência, o habitante do peito, o homem interior, o grande juiz e 
árbitro da nossa conduta" (Smith, 1999: 166). Não são as reflexões sobre a ordem social que corrigem o excesso de amor de si. São as reflexões sobre as ações e condutas de cada um nessa sociedade: “... o amor ao que é honrado e nobre, à grandeza, dignidade e superioridade de nossos próprios caracteres" (Smith, 1999: 167). Essa razão do espectador imparcial é a que nos chama à noite para prestar contas do movimento do dia; faz-nos ver que somos apenas um na multidão, nada melhor que os outros, e que se fomos egoístas, seremos objetos apropriados de ressentimento e execração.

A grande escola da vida é a do autodomínio, duramente exercido nos conflitos diários. Somente a partir dessa educação exemplar o agente pode emular o suposto espectador, que serve de juiz imparcial das suas condutas. A formação desse juiz é lenta, gradual e progressiva. Todo dia melhora-se um traço e corrige-se uma falha (Smith, 1999: $309,310)$. O costume leva à identificação quase completa entre o agente e o seu espectador. O agente até passa a sentir somente guiado por esse grande árbitro (Smith, 1999: 176, 177).

No convívio social, na presença do espectador real, o espectador abstrato e ideal aprende e se molda. A solidão e a conversa com um amigo podem não corrigir as distorções sentimentais, já que a tendência é privilegiar os padrões já estabelecidos. O contato com espectadores estranhos melhora a educação do juiz interior (Smith, 1999: 185).

O espectador precisa ser imparcial porque constitui a sua natureza a ponderação das emoções parciais sentidas. Não é imparcial no sentido de seguir uma máxima moral, seja a percepção da necessidade de maximizar a satisfação dos desejos da teoria utilitarista, sejam os princípios de justiça na posição original de Rawls. ${ }^{6}$ Ao contrário, o espectador é imparcial porque obriga a reconhecer que a satisfação pessoal dos desejos pode não ser compartilhada pelos outros. Uma ação com efeitos benéficos (úteis) pode não ser moralmente aceita na ótica do espectador imparcial. Isso porque não resta definido o bem, já que até a prudência excessiva, como no caso do indivíduo avesso ao risco, que pode ser recomendada como virtude para as ações nos negócios (econômicos), pode atrapalhar o empreendimento.

\footnotetext{
${ }^{6}$ No sentido de regra moral, a mais importante da tradição filosófica é o imperativo categórico de Kant. Para uma associação entre o espectador imparcial e o imperativo categórico, ver Tugendhat (2000: 324, 325, 340 e 341). Para uma defesa da associação entre a ética de Kant e o utilitarismo, ver Hare (1998, 201 em diante). Como já referido, Rawls (1997: §40) também faz a interpretação kantiana da justiça como equidade.
} 
Como o espectador é imparcial nesse sentido de mediador contínuo, sem base dedutiva formal, não é possível atribuir característica psicológica definida. A todo o momento procura corrigir a tendência a determinado tipo psicológico, ora egoísta, ora altruísta, ora em algum ponto entre esses dois extremos. Por isso que o espectador imparcial de Smith não é capaz de conciliar o altruísmo perfeito suscitado por Rawls. Como afirma Smith (1999: 112), o interesse pela multidão é o que sentimos por qualquer pessoa meramente por ser nosso semelhante. Decorre mais do compartilhar emoções, que produz a solidariedade geral, e não de alguma filosofia que defina cabalmente qual deveria ser o estado de bem-estar.

Smith não se colocou inteiramente oscilante com vistas ao desígnio humano. Recomendou o estudo das virtudes humanas como matéria de filosofia moral. As virtudes da prudência, justiça e beneficência, a primeira associada ao senso de conveniência, e as outras duas ao senso de mérito ou demérito, sendo que essas últimas produzem os efeitos agradáveis referidos por Hume, ainda que não escapem de serem julgadas na ótica do espectador imparcial (Smith, 1999: 329). Relevante para o entendimento da ótica do espectador imparcial é a virtude do autodomínio e a da sensibilidade, a primeira por recomendar a redução do excesso de amor por si, e a segunda por recomendar o partilhar emoções. ${ }^{7}$

Mais importante é que Smith realça a capacidade humana de sentir emoções compartilhadas e ponderadas pelo suposto espectador imparcial bem informado. Para Smith, e também para Hume, a solidariedade humana é natural e evidente, percepção contrária a do abstrato estado original de guerra entre os indivíduos (Hobbes, 1997). O sumo bem do utilitarismo foi fixado como o objetivo a ser alcançado, dada a relevância que se confere à necessidade de se buscar o estado de felicidade. No entanto, para Smith e Hume, o estado de felicidade é corrente na vida humana, sendo o objetivo se manter nele, e não buscá-lo. É por isso que os rebaixamentos da condição original de felicidade influenciam mais o sofredor do que os melhoramentos ao beneficiado.

\footnotetext{
7 A melhor descrição da importância das atitudes virtuosas na Ética de Smith consta na obra de Tugendhat (2000: décima quinta lição). Esse autor defende que o fato fundamental foi o de Smith assentar o conteúdo das virtudes sobre um princípio moral de caráter universal, vinculado ao espectador imparcial, que é o mesmo princípio de Kant (Ibid.: 325).
} 
Assim, o espectador imparcial que pondera afeições e virtudes, especialmente as ligadas ao senso de conveniência, que constitui elemento crucial da Ética de Smith, não pode ser diretamente associado ao princípio clássico do utilitarismo. ${ }^{8}$ Esse mecanismo não aparece sancionando a interpretação dada por Rawls acerca do observador ideal utilitarista.

\section{O observador ideal utilitarista e o espectador imparcial}

A descrição acima denota o que se pode observar de diferente entre o observador ideal de Rawls e o espectador imparcial de Smith, embora isso não seja uma tarefa fácil em visões tão complexas da natureza humana e da vida em sociedade, em éticas que ultrapassam em muito a focalizada contradição entre esses mecanismos.

O primeiro aspecto a se considerar é que o espectador imparcial desempenha um papel mais complexo do que o observador ideal utilitarista. Não se discorda que o espectador imparcial, influenciado por um grau de satisfação média, pode adotar a medida da utilidade para avaliar os conflitos morais. A questão é que, do ponto de vista do espectador, é possível observar outras integrações morais distintas das evidências de aplicação do princípio da utilidade. Isso fica claro quando as definições expostas por Smith, e também por Rawls, direcionam a contemplação utilitarista para a beleza sistêmica. Ao espectador imparcial se apresenta um campo de visão para além da utilidade dos objetos, permitindo averiguar a situação segundo a conveniência, consoante os motivos dos agentes, os quais envolvem profundas reflexões acerca de sentimentos, afeições e psicologias individuais, mais abrangentes do que o ponto de vista do observador ideal utilitarista.

\footnotetext{
8 Sen (2003a) afirma, corretamente, que o espectador imparcial de Smith não é o utilitarista clássico disfarçado de observador real. O véu de ignorância formulado por Rawls é poderoso para rebaixar os interesses e objetivos pessoais. Entretanto, como compara Sen, não garante um exame aberto para além dos valores locais e provincianos do grupo focal. O espectador imparcial de Smith permite essa abertura. Observa-se, ainda, que o observador ideal utilitarista na posição original remete para a tese utilitarista do "teorema do observador imparcial" de John C. Harsanyi (2002), rejeitada por Rawls (2002, 7n4; 2003, 137n19 e 14ln22) e Sugden (2002, nota 9).
} 
O segundo aspecto diz respeito ao caráter contingente do espectador imparcial. É relevante destacar o distanciamento dessa posição contingente da necessidade de impor regra racional. Vale dizer, o espectador imparcial segue rumo indutivo, apreendendo as distinções morais a cada situação que se apresenta, ao longo de uma vida, o que é distinto da proposição de princípios racionais para o prosseguimento dedutivo. Essa situação contradiz a definiçãa de Rawls, que considera o observador ideal amplo conhecedor das posições sociais. Ao contrário, a vivência de cada momento, com a presença do espectador imparcial, corrobora a proposição do véu de ignorância; concorda que o conhecimento completo da posição social, de si e dos outros, não é possível diante da complexidade das afeições compartilhadas. $\mathrm{O}$ espectador imparcial bem informado percebe que não deve se guiar apenas pelo seu autointeresse, o qual ele vê como aplicado para o restante da humanidade, pois essa posição é reconhecida como o problema psicológico do egoísmo e, no outro extremo, pelo altruísmo perfeito. $\mathrm{O}$ espectador imparcial aprende no convívio ao se despir dos interesses parciais envolvidos, para avaliar a situação, assim como fazem os participantes da posição original cobertos com o suposto véu de ignorância.

Em terceiro, a fusão de desejos procede, mas não em um só desejo social. O espectador imparcial refreia o indivíduo para que ele adote a posição que seria a mais conveniente para a situação. Assim, podemos entender o que seria uma situação normal, ou seja, a situação que correspondente a uma média social. No entanto, essa fusão é temporária e não permite fixar concepção única de bem. O espectador imparcial, que está constantemente aprendendo na convivência social diária, está preparado para rever a posição a qualquer momento, ainda mais que o bem escolhido não é determinante como padrão de desejo. Não se coaduna com a visão do espectador imparcial ter em mente determinada preferência para todas as situações. A avaliação sempre fica em aberto (Sen, 2003a).

Em quarto, a benevolência consiste em virtude ligada ao senso de mérito ou demérito. Somente pode ter relação com o cuidado das pessoas próximas, quando presente a convivência mediada pelo espectador imparcial, já que a benevolência universal se amolda mais ao prazer estético com a beleza do sistema. Esse sentido envolve questionar, por exemplo, o caráter da caridade e da pobreza como não ligados estritamente ao objetivo de maximizar o bem-estar, mas 
também ao prazer estético com a beleza do sistema, o desejo de ser notado, e, sobretudo, aos sentimentos locais, entre pessoas próximas e no mesmo lugar, revisando a percepção acerca da benevolência universal (Smith, 1999, 6ª II; Birch, 1998).

Sobretudo, a primazia do justo, tal como requisitada por Rawls, deve ser entendida no âmbito do racionalismo kantiano, em oposição ao caráter contingente do espectador imparcial. Não há, em Smith, expressão do espectador imparcial com capacidade racional (teórica e prática). O espectador imparcial considera constantemente as afeições envolvidas, compartilhadas ou conflituosas. A razão ou filosofia é empregada para conceder outra feição ao teatro da vida, como o caso do princípio da utilidade recomendando a busca pelo melhor bem-estar. Veja-se, por exemplo, o caso do ressentimento como reação a uma ação ou conduta julgada incorreta e prejudicial, o qual fundamenta o senso de justiça (Smith, 1999: 102-6). O ressentimento do sofredor da ação, a indignação do espectador imparcial e o sentimento de culpa do agressor decorrem de conflitos sentimentais, no compartilhar afeições, sentido que determina fundamento para o senso de justiça diferente do procedimental proposto por Rawls.

Contudo, permanece o desafio proposto por Rawls, de interpor a concepção psicológica de que se trata. Rawls (2005: 27) reconhece o longo caminho percorrido pelos filósofos sentimentalistas, especialmente Hume, para estabelecer a concepção psicológica do indivíduo. E também mostra as limitações do tipo psicológico do utilitarismo, do sujeito maximizador do bem-estar. Por isso a necessidade de Rawls discutir os fundamentos psicológicos do utilitarismo e contrapô-los com a teoria da justiça como equidade. E é também por isso que as bases da reunião dos participantes na posição original somente podem ser questionadas ao se introduzir modificações na tipologia psicológica fundante. Com essa última temática saltamos para além do confronto entre o espectador imparcial e o observador ideal. O campo de estudo se alarga; envolve conhecer e contrapor doutrinas morais abrangentes. Rawls, nesse particular, contrapõe o racionalismo construtivista ao intuicionismo e ao utilitarismo, o que envolve o vasto campo de conhecer o formulado nessas doutrinas morais. Smith, por sua vez, questiona os sistemas que consideram a natureza da virtude e os sistemas formados em decorrência do princípio de aprovação escolhido. Essa abordagem amplia em muito as nossas pretensões, o que pudemos até aqui examinar. 


\section{Considerações finais}

Questionamos se o espectador imparcial de Smith seria o observador ideal formulado por Rawls. A resposta não consiste em simples sim ou não. Eles se confluem quando se tem em vista a crítica ao utilitarismo como doutrina moral para decidir acerca dos conflitos morais. Porém, divergem quando se alarga o campo para julgar as situações morais para além da percepção utilitária, também no campo da conveniência ou inconveniência da ação ou conduta, e não só em decorrência do futuro mérito ou demérito da ação ou conduta.

Podemos afirmar que o observador ideal foi construído por Rawls para instruir o mecanismo de agregação dos desejos individuais do utilitarismo, permitindo a contraposição ao procedimento de acordo na posição original sobre os dois princípios de justiça. Ao aderir à tese de satisfazer o desejo médio da sociedade, o observador ideal perde a capacidade de ser imparcial. Nesse sentido, a tese utilitarista é antecipada como evidente para todas as pessoas. Torna-se irrelevante abordar a imparcialidade; o princípio da utilidade determina a ação ou conduta para o objetivo parcial, no caso, para a satisfação média dos desejos. Não é o caso da teoria da justiça como equidade, pois as condições da posição original, especialmente a restrição imposta pelo véu de ignorância, garantem que não serão adotadas teses parciais para a estrutura básica da sociedade bem organizada. As condições vigentes, no tipo de sociedade proposta por Rawls, são coerentes com os dois princípios de justiça.

O espectador imparcial de Smith, por sua vez, não permite fixar a ação ou conduta na ótica utilitarista. A todo o momento, no compartilhar emoções, está pronto para reavaliar as ações e condutas. Então, significa um requisito essencial para ser espectador imparcial, isto é, a de estar aberto aos conflitos sentimentais sem se fixar em determinada regra de conduta parcial. Nesse sentido, até os dois princípios de justiça rawlsianos, extraídos de uma lista de princípios sobre o justo vigente na sociedade bem organizada, estão abertos para o reexame contingente, dependentes de uma situação atual de compartilhar afeições, pois nada pode escapar do ponto de vista do espectador imparcial.

Não deve pairar dúvida de que o espectador imparcial atua para a formação moral do indivíduo ao longo de toda a sua vida. Como vivemos em um sistema de mercado, por exemplo, é de se supor que 
as convivências sociais seguem as regras desse sistema, sob pena de exclusão, moldando o espectador imparcial nesse ambiente. $\mathrm{O}$ conjunto de indivíduos, buscando um acordo nesse sistema de mercado, também sente a presença do espectador imparcial, adaptado segundo a convivência entre esses indivíduos.

Contudo, a visão do espectador imparcial não se informa apenas na razão do sistema, na que conduz à tese utilitarista, na medida em que é racional a satisfação do bem-estar, a busca por melhores condições materiais de vida e a maximização da utilidade do homo economicus. Smith reconhece que isso ocorre corriqueiramente na vida, pois é evidente a agitação intensa da população em busca por melhores condições de vida. Porém, há o intercâmbio sentimental, a simpatia com as emoções compartilhadas, mediada pelo espectador imparcial, uma vida sentimental mais decisiva nas decisões morais do que a vida exclusiva num sistema de trocas, onde não há necessidade de laços de bondosa amizade.

Na posição original, sem disputar a distribuição das diferentes posições na sociedade, a visão do espectador imparcial está presente no conjunto de regras racionais vigentes de justiça oferecidas para escolha. As regras descritas por Rawls representam o que se entende por sociedade democrática bem organizada para a liberdade e equidade, argumentação com possibilidade de ser racionalmente discutida, disposta, portanto, para sustentar a escolha dos dois propostos princípios de justiça. A partir dessa descoberta se opera de forma dedutiva, utilizando as regras de justiça conhecidas para testar as instituições sociais, conferindo coerência à teoria de Rawls e compatibilidade com a teoria do espectador imparcial de Smith.

Porém, mesmo delimitando o campo de visão do espectador imparcial à racionalidade presente nessa teorização, ainda assim não há como assegurar futuras modificações nas condições sociais e, em decorrência, no conjunto de regras oferecido para a seleção. A tarefa de questionar as regras vigentes é inerente ao espectador imparcial; decorre da constante convivência social ao longo da vida. E é ainda mais questionador o espectador imparcial moldado pelos conflitos emocionais, pois não se podem negar as amplas evidências de reações emocionais no convívio humano; como prova o choro do mais profundo filósofo perante a injustiça. 


\section{Referências}

BIANCHI, A. M. A Pré-História da Economia: De Maquiavel a Smith. São Paulo: Hucitec, 1988.

BENTHAM, J. [1823] An introduction to the principles of morals and legislation. 2. ed. Londres: Prometheus Books, 1988.

BIRCH, T. D. "An analysis of Adam Smith's theory of charity and the problems of the poor". Eastern Economic Journal, Bloomsburg, 24 (1): 25-41, 1998.

CERQUEIRA, H E. A. da G. "Sobre a Filosofia Moral de Adam Smith". XXXIV Encontro Nacional de Economia. Disponível: http://ideas.repec.org/e/pce10.html, Acesso: 01/02/2007, 2006.

CRISP, R. "Equality, Priority, and Compassion”. Ethics, 113 (4): 745-763, 2003.

DARWALL, S. "Sympathetic liberalism: Recent work on Adam Smith". Philosophy and Public Affairs, 28(2): 139-164, 1999.

FREY, R. G. Utilitarismo. In OUTHWHAITE, W., BOTTOMORE, T. (eds). Dicionário do pensamento social do século XX. Rio de Janeiro: Zahar, p. 785-787, 1996.

GANEM, Â. "O mercado como teoria da sociedade: a radicalidade filosófica de Adam Smith". IV Encontro Nacional de Economia Política, UFRGS, Porto Alegre-RS. Disponível: http://www.race. nuca.ie.ufrj.br/nuca-wp/autor/ganem3.exe. Acesso: 01/ 03/2001, 1999.

HARE, R. M. Ética: problemas e propostas. São Paulo: Ed. UNESP, 1998.

HARSANYI, J. C. "Morality and the theory of rational behaviour." In Utilitarianism and Beyond. Sen, Amartya \& Williams, Bernard (ed.). Cambridge: Cambridge U.P. p. 39-62, 2002.

HARSANYI, J. C. "Cardinal Welfare, Individualistic Ethics, and Interpersonal Comparisons of Utility". Journal of Political Economy, 63, 1955.

HEILBRONER, R. L. "The socialization of the individual in Adam Smith." History of Political Economy, 14(3): 427-439, 1982.

HOBBES, T. Leviatã. São Paulo: Nova Cultural (Coleção: Os Pensadores), 1997.

HUME, D. Uma Investigação Sobre os Princípios da Moral. Campinas: UNICAMP, 1995.

HUME, D. Tratado da Natureza Humana: uma tentativa de introduzir o método experimental de raciocínio nos assuntos morais. Trad. Débora Danowsky, 2a ed. São Paulo: Ed. UNESP, 2009.

KONOW, J. Is Fairness in the Eye of the Beholder? An Impartial Spectator Analysis of Justice. MPRA Paper $n^{\circ}$ 2730. Disponível: http://mpra.ub.uni-muenchen.de/2730/, 2006. Acesso: 15/11/2007.

PRIETO, J. H. El Sistema de La Simpatia de Adam Smith: uma alternativa liberal olvidada por John Rawls. Documento CEDE 2006-17. Disponível: http://economia.uniandes.edu.co/ investigaciones_y_publicaciones/CEDE/Publicaciones/documentos_cede/2006/alternativa_liberal_olvidada_por_john_rawls, 2006. Acesso: 09/10/2007.

RAPHAEL, D. D. Adam Smith 1790: the man recalled; the philosopher revived. In Adam Smith Reviewed. JONES, Peter; SKINNER, Andrew S. (ed.), Edinburgh: University Press, 1992.

RAWLS, J. The Sense of Justice. The Philosophical Review. 72(3): 281-305, 1963.

. Some Reasons for the Maximin Criterion. The American Economic Review, 64 (2): 141$146,1974$.

. Uma Teoria da Justiça. São Paulo: Martins Fontes, 1997.

Lectures on the History of the Moral Philosophy. Editado por Barbara Herman. London:

Harvard, 2000. . Justiça e Democracia. São Paulo: Martins Fontes, 2002.

. Justiça como Equidade: Uma Reformulação. São Paulo: Martins Fontes, 2003.

. História da Filosofia Moral. São Paulo: Martins Fontes, 2005.

Estud. Econ., São Paulo, vol.45, n.1, p. 185-214, jan.-mar. 2015

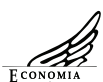


SEN, A. Equality of what? The Tanner Lectures on Human Values, 1979.

. Well-Being, agency and freedom (the Dewey Lectures, 1984). The Journal of Philosophy, 82 (4): 169-221, 1985.

Sobre Ética e Economia. São Paulo: Schwarcz, 1999.

. Imparcialidade Aberta e Fechada. Alceu. PUC Rio. v 3, n. 6, p. 5-30. Disponível: http:// publique.rdc.puc-rio.br/revistaalceu/cgi/cgilua.exe/sys/start.htm?tpl=home,

2003a. Acesso: 01/02/2007.

. Development as Capability Expansion. In: Fukuda-Parr S, et al. Readings in Human Development. New Delhi: Oxford University Press, 2003b.

. "Adam Smith and the contemporary world". Erasmus Journal for Philosophy and Economics. Vol. 3, No 1, p. 50-67. Disponível: http://ejpe.org/pdf/3-1-art-3.pdf, 2010. Acesso: 26/07/2010.

SUGDEN, R. Beyond Sympathy and Empathy: Adam Smith's concept of fellow-feeling. Economics and Philosophy, 18: 63-87, 2002.

SMITH, A. Teoria dos Sentimentos Morais. São Paulo: Martins Fontes, 1999.

TUGENDATH, E. Lições sobre Ética. Petrópolis: Ed. Vozes, 2000. 